\title{
TUMOR MISTO BENÍGNO DE GLÂNDULAS SALIVARES
}

Thiago Vinícius Sehn SLAVIERO, Estela Tonetto RODRIGUES, Iris SAWAZAKI, Adriane de Castro Martinez MARTINS, Hakihito Belcaro MARTINS

O Adenoma Pleomorfo (AP) constitui cerca de $50 \%$ de todas as neoplasias originárias das glândulas salivares maiores e menores. Clinicamente nota-se uma massa nodular firme, de crescimento lento e indolor. Este nódulo geralmente apresenta cor avermelhada, acomete principalmente a região de palato duro e palato mole, e pode ocorrer em qualquer idade, principalmente em adultos. Este trabalho tem como objetivo descrever um caso clínico de uma paciente encaminhada a clinica de Estomatologia da Unioeste que apresentava as principais características clínicas, radiográficas e histopatológicas do AP. A paciente do gênero feminino, 27 anos, apresentou uma lesão nodular expansiva, com cerca de $3 \mathrm{~cm}$ de diâmetro localizada em palato duro e palato mole, do lado direito entre molar e pré-molar, com coloração semelhante da mucosa normal, consistência firme à palpação e aproximadamente 3 anos de evolução. Após biópsia incisional, foi realizado procedimento cirúrgico para remoção total da lesão. A existência de características clínicas compatíveis com o Adenoma Pleomorfo, não descarta a necessidade de confirmação do diagnóstico através do exame histopatológico. O melhor tratamento para esta patologia consiste na sua excisão cirúrgica, havendo risco de recidiva, principalmente em casos de envolvimento de glândulas maiores, devendo-se então fazer o acompanhamento periódico do paciente.

Palavras-chave: Adenoma pleomorfo; Glândulas salivares; Diagnóstico diferencial. 